\title{
FORMULATED MICROBIAL CONSORTIUM AS INOCULANT FOR AGARWOOD INDUCTION
}

\author{
Justin S*, Lihan S, Elvis-Sulang MR \& Chiew TS \\ Faculty of Resource Science and Technology, Universiti Malaysia Sarawak, 94300 Kota Samarahan, Sarawak, Malaysia \\ *sabellaj.biotech@gmail.com
}

Submitted May 2019; accepted August 2019

\begin{abstract}
Agarwood or gaharu is well known as the most valuable resinous heartwood that occurs in trees of Aquilaria species. Depletion of the wild resource from the jungle leads to the high price of agarwood. Thus, there is an urgent need to produce agarwood sustainably through agarwood cultivation to meet the global demand and induction. This research was conducted to formulate microbial consortia that can be used as fungal inoculants for agarwood induction in Aquilaria species. The effectiveness of formulated microbial consortia was observed based on the colour and mean length of infected zone formation after a three and six months inoculation periods in each wet and dry season, respectively. Aquilaria sp. was inoculated with three types of formulated fungal inoculants and negative control by using the bottle drip method. The findings showed that F3 inoculant (a combination of Trichoderma sp., Lasiodiplodia sp. and Curvularia sp.) was the most potential fungal inoculant for agarwood formation based on the darkest colour and largest mean length of the infected zone, after a three and six months inoculation periods for both wet and dry seasons. The formulated inoculant is recommended for further development as agarwood fungal inoculant to induce agarwood artificially for future sustainable supply of agarwood.
\end{abstract}

Keywords: Aquilaria, fungal inoculants, bottle drip method, infected zone, seasons

\section{INTRODUCTION}

Agarwood is the dark resinous heartwood that occurrs in the trees from Thymelaeaceae family including Aquilaria, Gonystulus and Gyrinops spp. According to a study by Naef (2011), agarwood is the most valuable resinous fragrant wood in the world. Its price could go up to USD100,000 per kilogram in the market for superior quality and high purity material. Furthermore, agarwood is not only well-known for its traits as perfumery ingredients and as aroma enhancers in food products, but also used as traditional medicine for centuries (Lee et al. 2016). In terms of medicinal uses of agarwood, it has been recommended as an anti-inflammatory agent to treat rheumatism, arthritis, body pain, asthma and gout (Hashim et al. 2016).

The lengthy inoculation periods in nature, which may take approximately 75 to 80 years before the highest yield can be observed, has restrained the supply of agarwood in the market (Naef 2011, Liu et al. 2013). Therefore, the uncertain supply and production of the agarwood is the main concern that needs to be addressed by researchers to meet the global demand for agarwood trading (Barden et al. 2000). In a natural forest, only $7-10 \%$ of the trees contain agarwood. The experienced specialist could only deduce the deposit of agarwood by mere observation on the intact stem. However, the trees still need to be fell and cut open to exactly determine the content and quality of the wood impregnated with resinoid. Aquilaria malaccensis has been listed as the most endangered species among all agarwood tree species, as stated in Appendix II of the Convention on Internal Trade in Endangered Species of Wild Fauna and Flora (CITES); unsustainable harvesting of Aquilaria sp. in natural forests led to near extinction (CITES 2015). Thus, the agarwood needs to be artificially induced to maintain the diversity of Aquilaria sp., and for the production of a larger amount of resin.

The cultivation of Aquilaria trees has been widely practiced in many countries to meet the demand for agarwood. Wounding, chemicals and microbes inducing agents have been used for artificial inoculation (Pojanagaroon \& Kaewrak 2005, Zhang et al. 2010). In 1952, 
Bhattacharyya reported the role of endophytic fungi in causing the inducement of agarwood formation in tree trunk. Thus, researchers have isolated several endophytes from the agarwood tree (Chhipa and Khaushik 2017). However, the production of agarwood in terms of ecological interaction between the host tree and the fungi is poorly understood. Besides, a good inoculum for gaharu production has not been discovered. Based on a study by Akhsan (2012), Fusarium solani was used to inoculate Aquilaria microcarpa. The results showed the formation of agarwood comparable with our current study. However, their inoculant contained only Fusarium solani which differs from our current study where formulated microbial consortia were used as fungal inoculants. Thus, the objective of this paper was to formulate microbial consortia from fungi, to be used as fungal inoculants. Besides, to identify the most potential fungal inoculants to induce agarwood in Aquilaria species, during the three and six months inoculation periods in both wet and dry seasons. Therefore, an examination of fungal inoculants on Aquilaria species and analysis of their microbial activities was necessary. This could help future researchers to develop and commercialise more effective microbial consortium with better potential to induce agarwood in Aquilaria species.

\section{MATERIALS AND METHODS}

\section{Fungi}

The six fungi isolates used in this study were Trichoderma sp., Curvularia sp., Aspergillus sp., Fusarium sp., Lasiodiplodia sp. and Penicillium. These fungi were isolated from agarwood and identified molecularly, and the endophytes were stored in the laboratory of the Faculty of Resource Science and Technology, Universiti Malaysia Sarawak, Sarawak.

\section{Microbial consortia preparation}

The microbial consortia were cultured and formulated by mixing equal proportions of fungi cultures onto potato dextrose agar (PDA) and incubated at $27{ }^{\circ} \mathrm{C}$ for seven days. The fungi tested consisted of six different species of fungi including Trichoderma sp., Curvularia sp., Aspergillus sp., Fusarium sp., Lasiodiplodia sp. and Penicillium sp. The activities of these formulated microbial consortia were determined through the observation of fungus symbiotic relationships in the media agar. Thus, three types of microbial consortia were chosen. Formulation 1 (F1) consists of the combination of Trichoderma sp. and Aspergillus sp., formulation 2 (F2) consists of the combination of Fusarium sp. and Penicillium sp., and formulation 3 (F3) consists of the combination of Trichoderma sp., Lasiodiplodia sp. and Curvularia sp. Sterile distilled water was used as a negative control in this study.

\section{Testing on agarwood trees}

The agarwood trees tested in this study were from the species of Aquilaria malaccensis. The Aquilaria sp. farm is located at Serian, Sarawak, Malaysia. The trees were tested with each of the three formulated microbial consortium and a negative control.

\section{Bottle drip method}

The Aquilaria sp. were wounded by drilling as described by Tang (2012), with modifications. The drilling on the Aquilaria sp. was carried out $21 \mathrm{~cm}$ above the ground. Each of the fungal inoculants, stored in waste plastic beverage bottle, was slowly dripped into the wounds. The hose connected to the cap of the plastic bottle was inserted into the hole of the Aquilaria sp. The plastic bottles were tied upside down to allow the inoculant to flow through the hose that has been inserted into the trees and sealed with clay. The cap of the bottle was sealed with parafilm to avoid leaking. The bottle drip method is shown in Figure 2. The Aquilaria sp. were wounded with a single hole and dripped with the formulated fungal inoculants, together with a negative control.

\section{Sample collection}

Wood samples of inoculated Aquilaria sp. were collected after a three and six months inoculation periods, performed for each wet and dry season.

\section{Measurement of infected zone formation}

The extent of the infected zone formed at wound sites was measured in a longitudinal direction. Observations based on heights and colour of infected zone were recorded for each of the three 
and six months inoculation periods in both wet and dry seasons.

\section{RESULTS AND DISCUSSION}

\section{Formulation of microbial consortium}

Three microbial consortia was formulated based on their symbiotic relationship, as they were able to simultaneously grow on PDA medium. The consortium was formulated by the combination of Trichoderma spirale and Aspergillus sp. (F1 inoculant), Fusarium and Penicillium sp. (F2 inoculant) and Trichoderma harzianum, Lasiodiplodia sp. and Curvularia sp. (F3 inoculant). These fungi symbiotically grew together in the medium in almost equal ratio. Previous studies have used fungal isolates in artificial infection of agarwood, using fungi such as Melanotus flavolivens, Phytium sp., Penicillium sp., Diplodia sp., Botryodyplodis sp., Lasiodiplodia sp. and Fusarium sp. (Gong \& Guo 2009, Zhang et al. 2014). Besides, Mohamed et al. (2010) reported the presence of fungal communities such as Curvularia, Cunninghamella, Trichoderma and Fusarium species in agarwood. These reports agreed with the current study where the fungal types used in these formulated microbial consortia were previously isolated from agarwood, and they had high potential to induce agarwood. Figure 1 showed formulated microbial consortium from different types of fungal species.

\section{Bottle drip method}

Bottle drip method was performed by hanging the bottle upside down, filled with each of the fungal inoculants, as the inoculant dripped through the hose that was inserted into the wounded trees. Figure 2 shows the bottle drip fungal inoculation method. In this study, applying a resin inducing agent, the formulated fungal inoculant, into the wound, was performed to increase the effectiveness of agarwood formation in a short term, compared to natural agarwood formation in a wild environment. Liu et al. (2013) stated that agarwood formation occurs slowly and infrequently in a natural environment which leads to insufficient supply for the market demand. Furthermore, without injury agarwood trees may not able to produce agarwood (Azah et al. 2013). Hence, the bottle drip fungal inoculation method was used in this study to prevent the closure of wound, as the presence of fungi aid in keeping the wound open and eventually disrupt the living

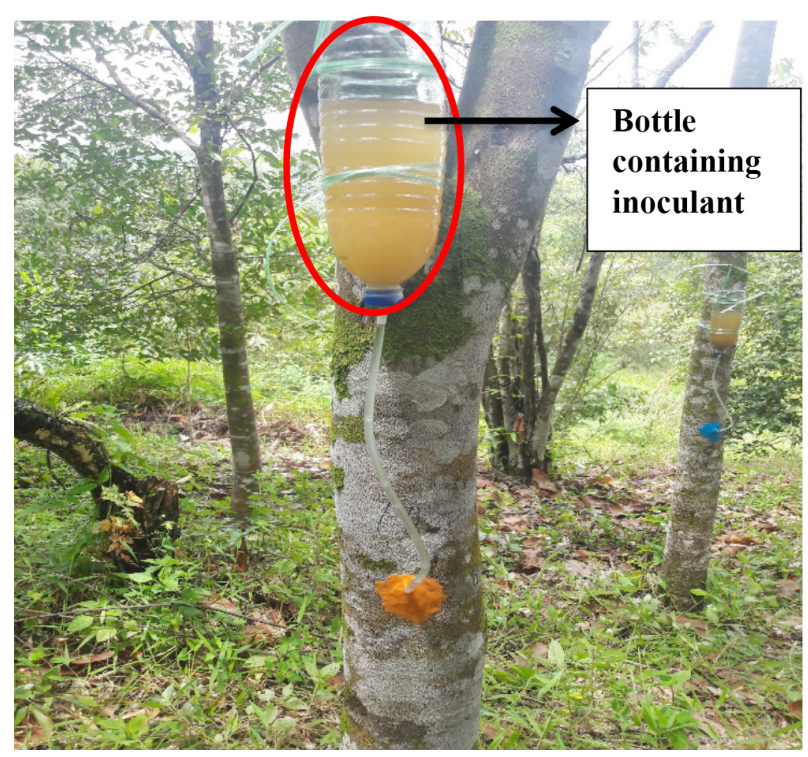

Figure 2 Bottle drip method

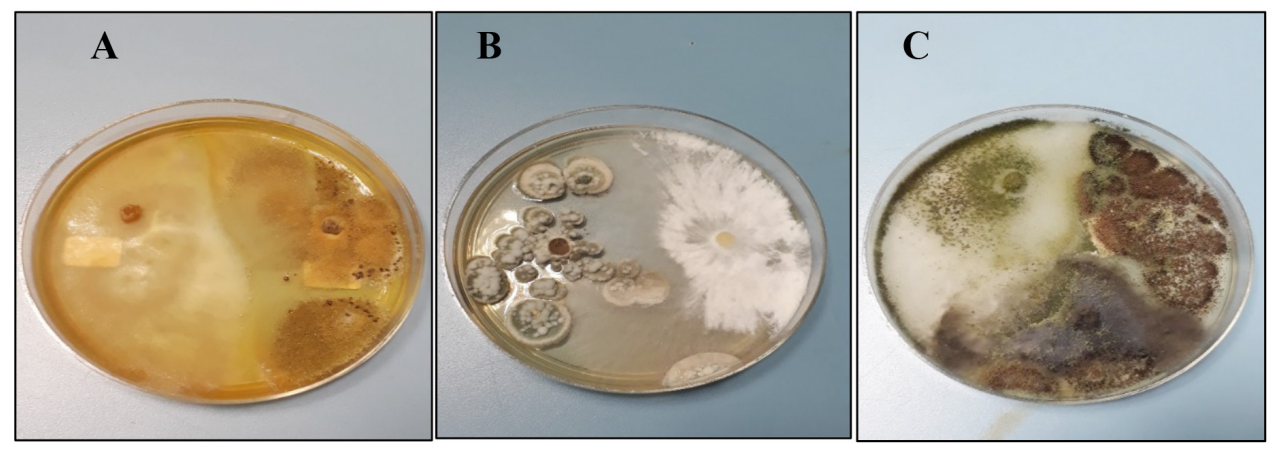

Figure 1 Microbial consortia formulation from different types of fungus species, (a) Trichoderma spirale and Aspergillus sp. [F1 inoculant] (b) Fusarium and Penicillium sp. [F2 inoculant] (c) Trichoderma harzianum, Lasiodiplodia sp. and Curvularia sp. [F3 inoculant] 
cells of agarwood trees which lead to agarwood formation. However, Azah et al. (2013) stated that there were uncertain similarities in the quality of agarwood production in cultivated agarwood trees induced by artificial technique, compared to harvest from natural agarwood trees.

\section{Measurement of infected zone formation}

The morphology infected zone formed in the inoculated Aquilaria sp. was done. Tables 1 and 2 show the colour changes along the infected zone within three and sixth months in each wet and dry season of inoculation periods, respectively. Resinous wood was represented by the oval shaped dark area, distinct from the white part of agarwood trees. The infected zone was described as the agarwood formation in Aquilaria sp. Tables 3 and 4 show the agarwood formation for each inoculated Aquilaria sp. in both wet and dry seasons, respectively. Based on morphological observation on the colour and length of the infected zone, there was evidence of the presence of agarwood in Aquilaria trees for every three and six months of inoculation periods. The darker zone formation is the result of resin accumulation in the wood of the tree over time (Liu et al. 2013). Due to fungal infection in the wounded bark, visible symptoms such as light brown, dark brown or black indicate the formation of resinous wood. Besides, Semangun (2001) stated that there was compatibility between pathogen gene and host gene due to fungal infection. Furthermore, factors such as tree age, genetic background, seasonal and environmental variation are also important in agarwood formation ( $\mathrm{Ng}$ et al. 1997). In this study, different seasonal inoculation periods were studied. The length of the infected zone formed on inoculated Aquilaria sp. was measured and recorded. In Figure 3, the average mean value of infection length (L) for three fungi inoculants and negative control in Aquilaria stem, after three and six months inoculation, is presented. Within the three months inoculation period for both wet and dry seasons, F3 inoculant showed the highest infection zone value $(6.3 \mathrm{~cm}$ and $12.1 \mathrm{~cm})$ followed by F1 $(6.2 \mathrm{~cm}$ and $10.9 \mathrm{~cm})$, F2 $(5.8 \mathrm{~cm}$ and $9.5 \mathrm{~cm})$ and negative control $(1.3 \mathrm{~cm}$ and $1.7 \mathrm{~cm})$, as shown in Tables 5 and 6 , respectively. The result of the one-way ANOVA showed that the mean length of infection among fungi inoculants was significantly different $(p<0.05)$. Environmental factors affected the infection length as inoculation periods took place within different seasons, i.e. wet and dry seasons. Tukey's test revealed that there was a significant difference, in the three and six

Table 1 Colour changes of inoculated zone for each of the fungi inoculants after three and sixth months of inoculation periods in wet season

\begin{tabular}{lll}
\hline \multirow{2}{*}{ Fungal inoculants } & \multicolumn{2}{c}{ Colour of inoculated zone } \\
\cline { 2 - 3 } & Three months & Six months \\
\hline F1 & Black with stripes & Dark brown \\
F2 & Brown & Pale brown \\
F3 & Black & Black \\
Negative control & Whitish yellow & Whitish yellow \\
\hline
\end{tabular}

Table 2 Colour changes of inoculated zone for each of the fungi inoculants after three and sixth months inoculation periods i in dry season

\begin{tabular}{lll}
\hline Fungal inoculants & \multicolumn{2}{c}{ Colour of inoculated zone } \\
\cline { 2 - 3 } & Three months & Six months \\
\hline F1 & Black & Dark brown \\
F2 & Brown & Pale brown \\
F3 & Black & Black \\
Negative control & Pale brown & Whitish yellow \\
\hline
\end{tabular}


Table 3 The widespread symptoms of infected zone after inoculation in wet season

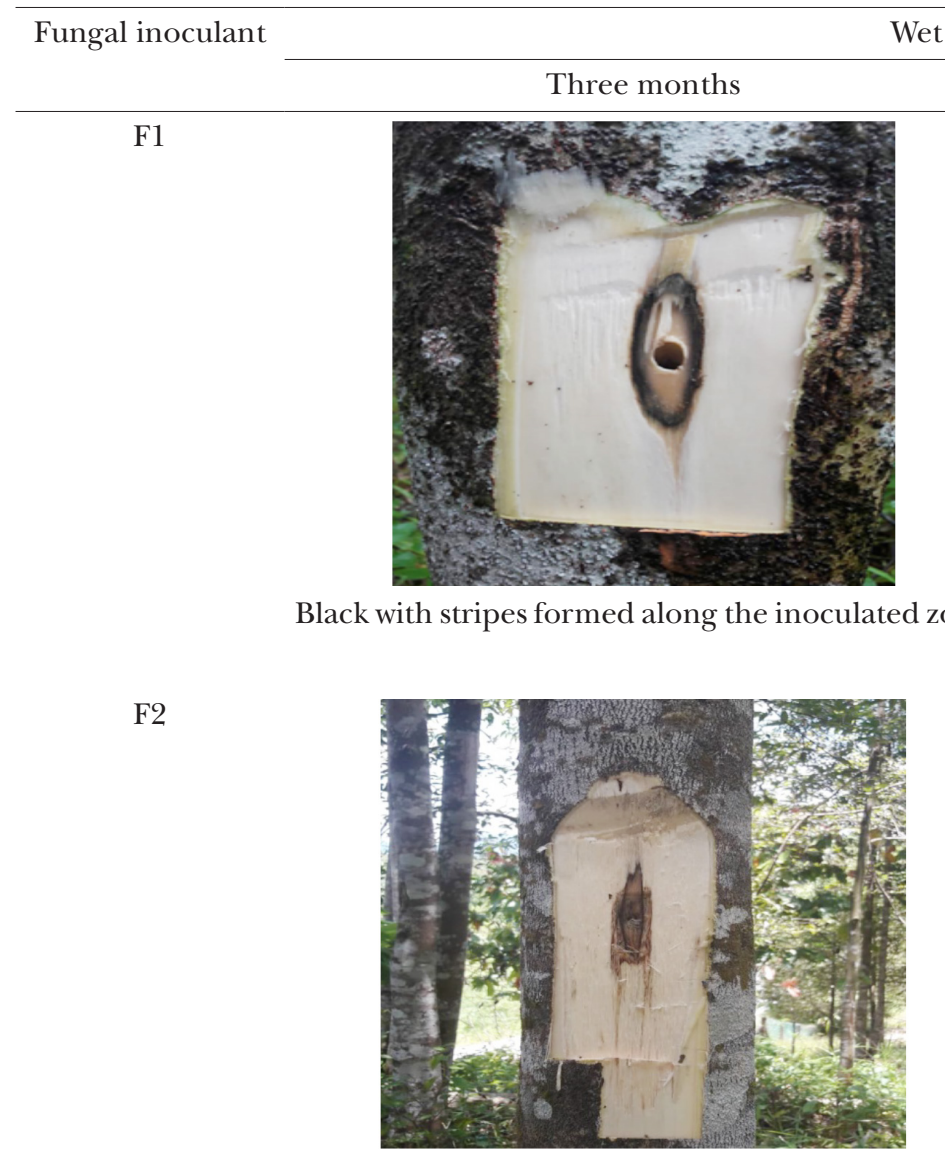

Brown colour formed along the inoculated zone

F3

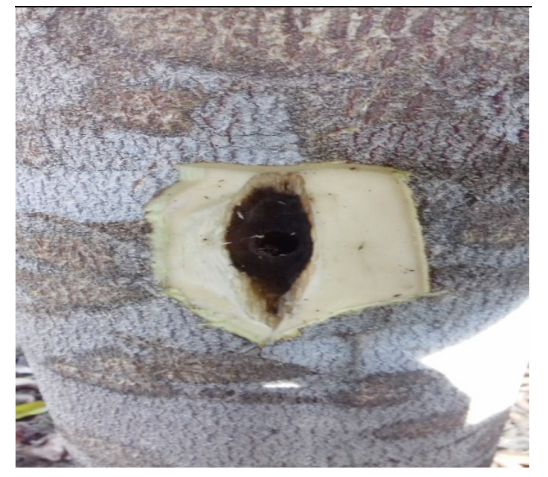

Black colour formed along the inoculated zone

Negative control

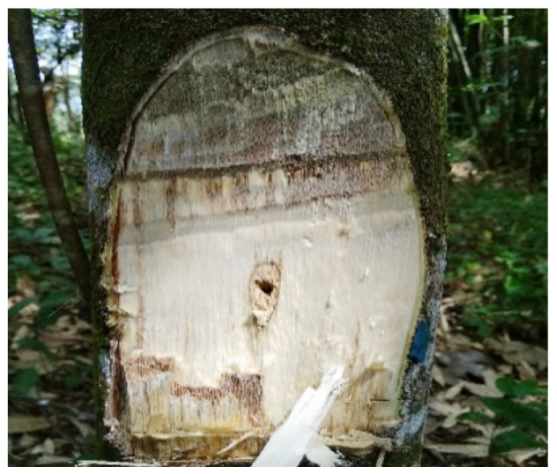

Whitish yellow formed along the inoculated zone
Wet season

Six months

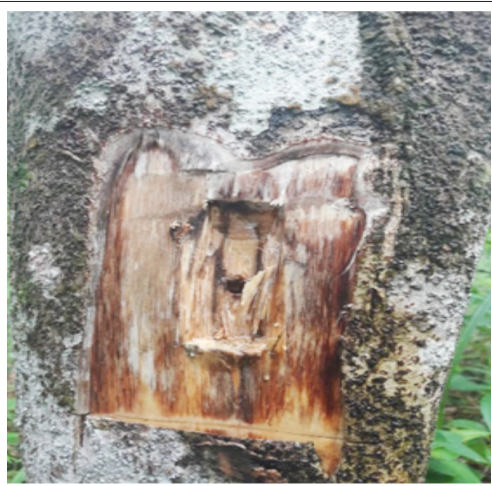

Colour changed to dark brown with stripes and symptoms deeper inside the stem

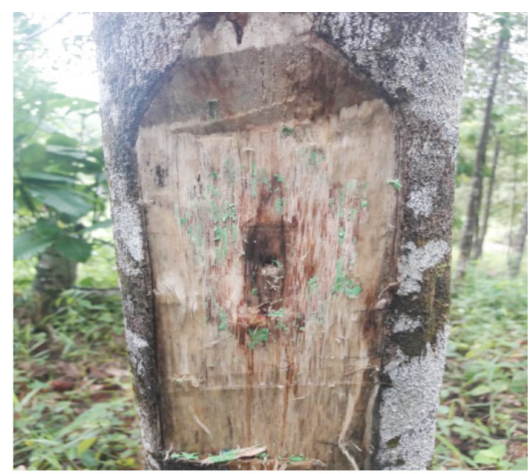

Colour changed to pale brown with stripes and symptoms deeper inside the stem

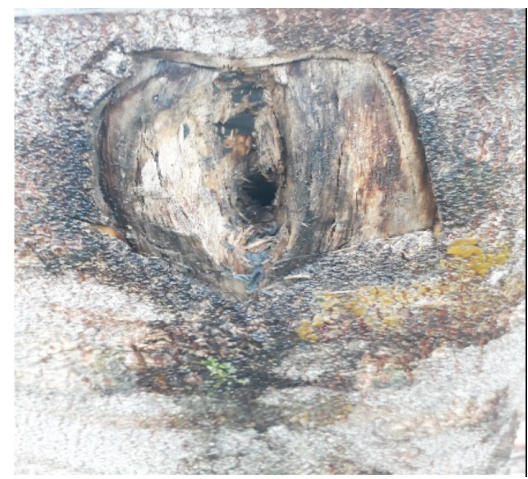

Black symptoms deeper inside the stem

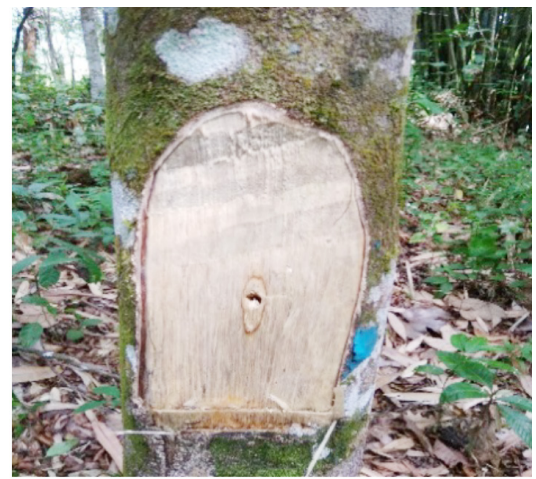

Whitish yellow symptoms deeper inside the stem 
Table 4 The widespread symptoms of infected zone after inoculation in dry season

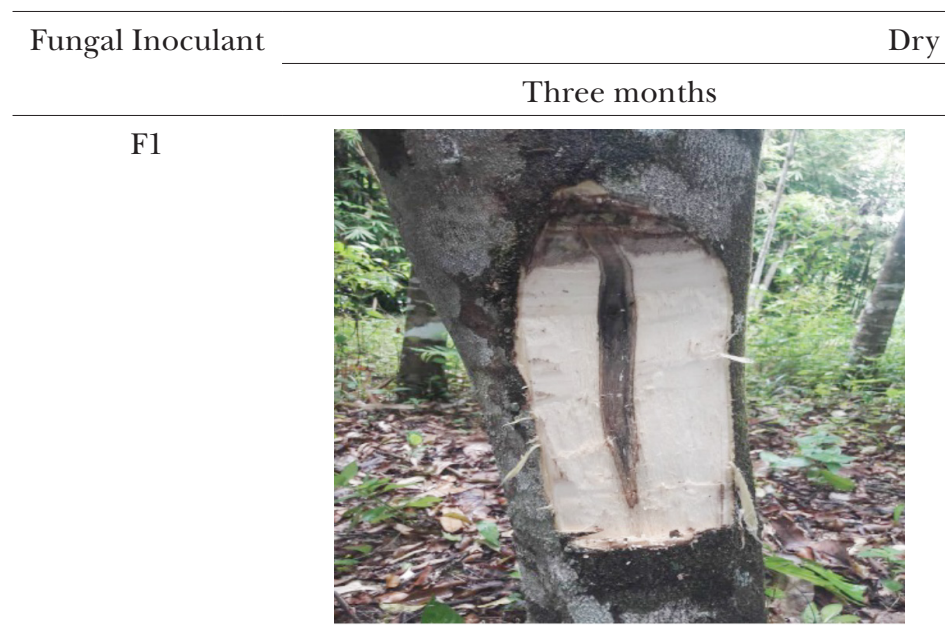

Black colour formed along the inoculated zone

F2

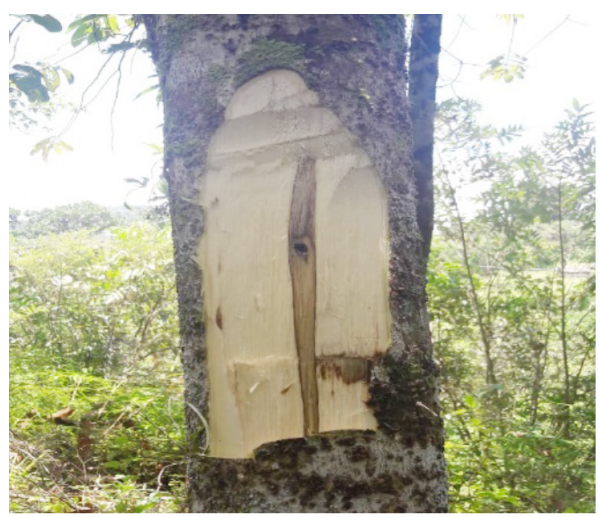

Brown colour formed along the inoculated zone

F3

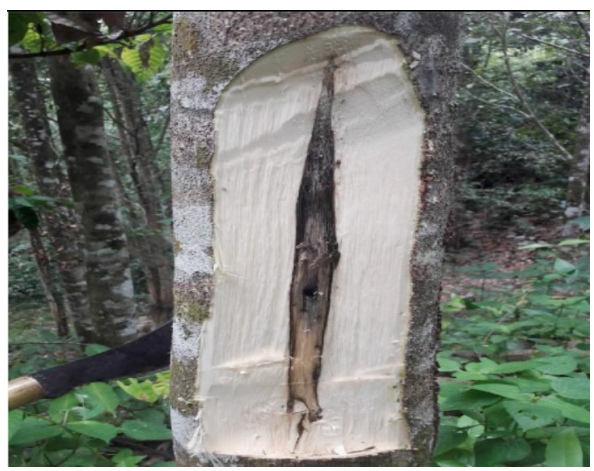

Black colour formed along the inoculated zone
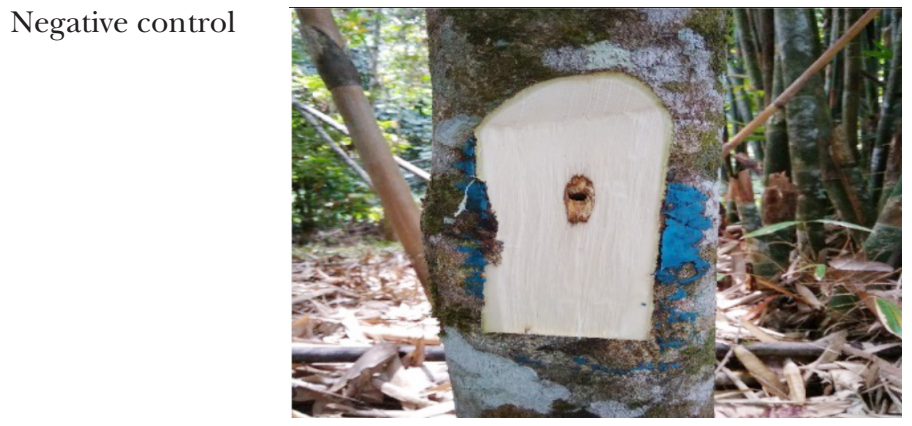

Pale brown formed along the inoculated zone
Dry season

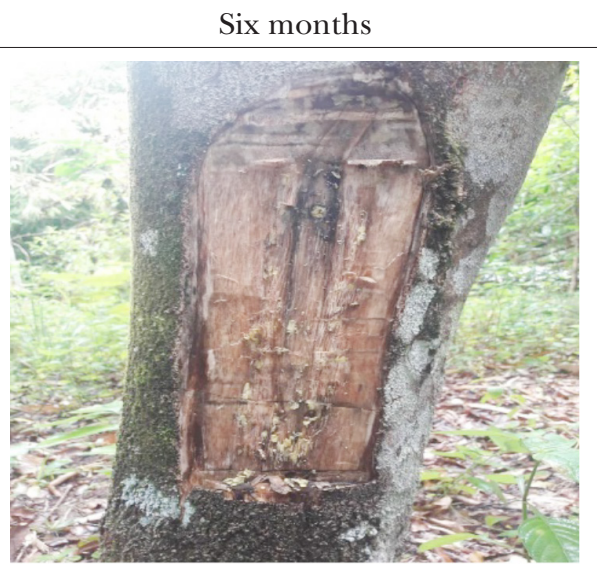

Colour changed to dark brown and symptoms deeper inside the stem

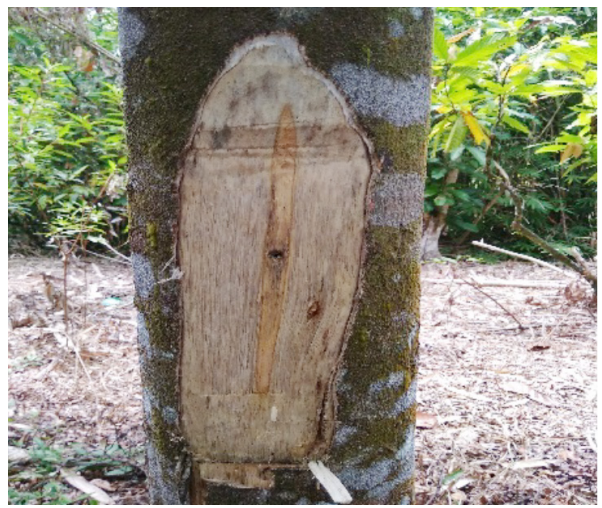

Colour changed to pale brown with stripes and symptoms deeper inside the stem

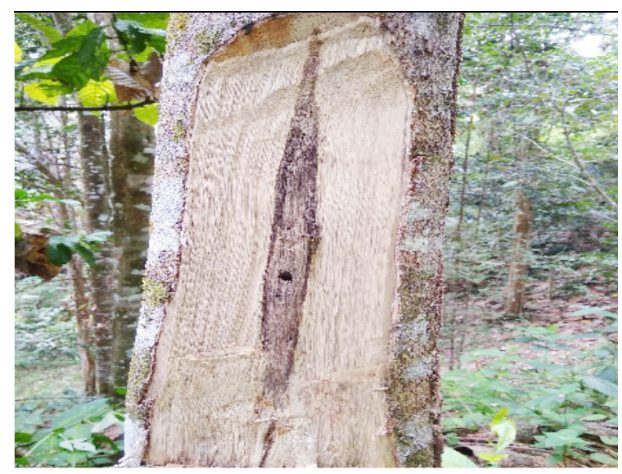

Black colour and symptoms deeper inside the stem

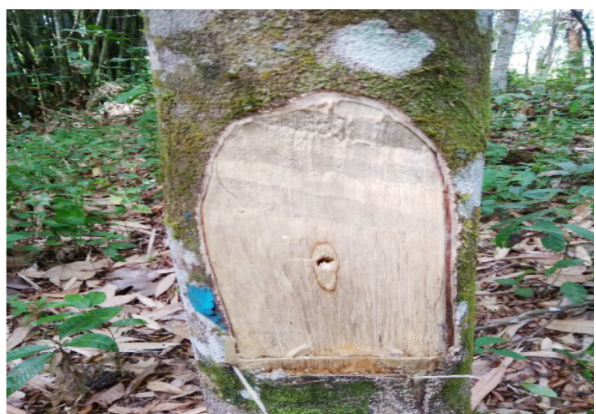

Pale brown deeper inside the stem 


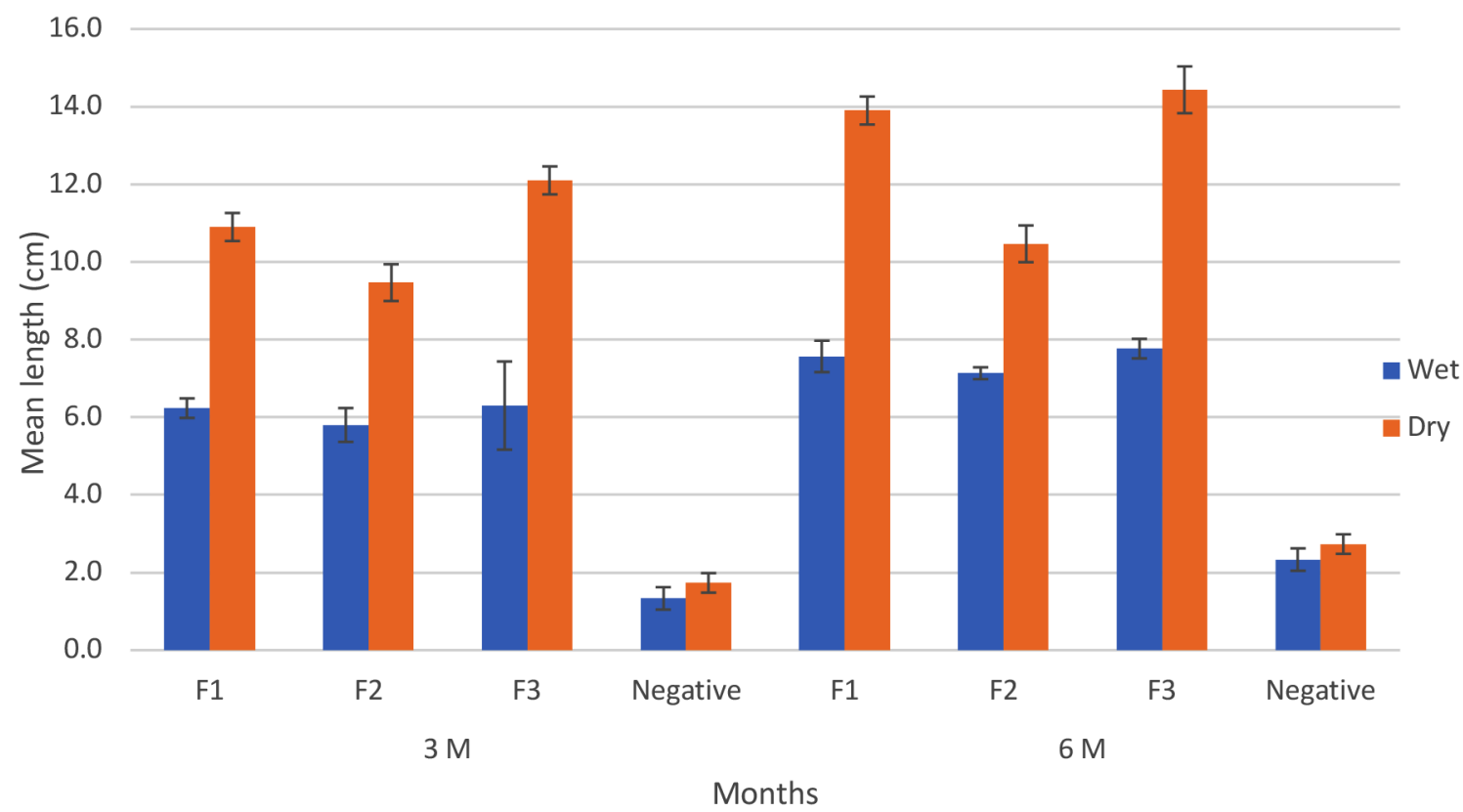

Figure 3 The average mean value of infection length (L) for three fungi inoculants and negative control in Aquilaria stem after three and six months inoculation periods for each wet and dry season; error bar represent standard deviations $(n=3)$

Table 5 Mean value of infection length (L) for three fungi inoculants and negative control in Aquilaria stem for three months inoculation periods in wet season

\begin{tabular}{cccc}
\hline Fungi inoculant tree & Replication, R & Infection length $(\mathrm{L}) / \mathrm{cm}$ & Mean value \\
\hline F1 & R1 & 6.0 & \\
& R2 & 6.2 & \\
R3 & 6.5 & \\
F2 & R1 & 6.2 & \\
& R2 & 6.0 & 6.3 \\
F3 & R3 & 6.1 & \\
& R1 & 5.3 & \\
& R2 & 5.0 & \\
& R3 & 7.1 & \\
Regative control & R2 & 6.8 & \\
& R3 & 1.0 & \\
\end{tabular}

months periods for both wet and dry seasons, between fungal inoculants and negative control. The inoculation carried out in the dry season was more effective compared to wet season based on the significant difference between wet and dry seasons. Hence, seasonal variation may affect the formation of agarwood. This current findings were concurrent with a previous study by Santoso et al. (2011), showing that agarwood production may decelerate due to humidity of the location. Although an equal volume of inoculant was injected into Aquilaria tree in both wet and dry seasons, the mechanism of fungal inoculants may not distribute well within the cells of the tree due to low transpiration rate during wet season. Based on current findings, F3 was the most potential fungi inoculant to induce agarwood formation in Aquilaria malaccensis. The F3 inoculant produced 
Table 6 Mean value of infection length (L) for three fungi inoculants and negative control in Aquilaria stem for three months inoculation periods in dry season

\begin{tabular}{cccc}
\hline Fungi inoculant tree & Replication, R & Infection length $(\mathrm{L}) / \mathrm{cm}$ & Mean value \\
\hline F1 & R1 & 11.0 & \\
R2 & R3 & 10.5 & \\
F2 & R1 & 11.2 & 9.5 \\
& R2 & 10.0 & \\
R3 & 9.1 & \\
F3 & R1 & 9.3 & \\
& R2 & 12.0 & 1.7 \\
R3 & 12.5 & \\
Regative control & R2 & 11.8 & \\
& R3 & 2.0 & \\
\hline
\end{tabular}

the darkest colour at the infected zone compared to other inoculants, and the mean value of the infection length gradually increased in each inoculation period of both wet and dry seasons. Karlinasari et al. (2015) stated that the darker the wood, the higher is the agarwood content.

\section{The burning smell of inoculated agarwood}

It is known that colour and fragrance indicate the presence of agarwood within trees. The formation of oleoresin relates to the aging of an early infection as the wood turned into a darker scented wood called 'agar' or 'gaharu', due to oleoresin accumulation. The deposited oleoresin within the wood, over time, gives a darker intensity to the infected wood (Rao \& Dayal 1992, Liu et al. 2013). Besides, the formation of the sweet smelling oleoresins is concentrated within the phloem part of the wood. In in this study, all the fungal inoculants induced agarwood in Aquilaria trees. The inoculated agarwood produced a distinct fragrance of sweet and uplifting woody aroma when burned. The F3 agarwood samples have obvious aroma compared to others, with or without burning. In Malaysia, gaharu wood is usually graded into several classes based on their colour, density, gaharu formation and unique scent (Azah et al. 2013). Thus, the study showed that F3 fungal inoculant had a higher possibility of agarwood formation in comparison with other fungal inoculants.

\section{CONGLUSION}

A total of three microbial consortia have been successfully formulated and tested for the induction of agarwood formation in Aquilaria species. The findings suggested that F3 inoculant containing Trichoderma sp., Lasiodiplodia sp. and Curvularia sp. was the most potential fungal inoculant to induce agarwood formation. In each three and six months inoculation periods, F3 inoculant produced the darkest colour and largest mean length of the infected zone in Aquilaria species, for both wet and dry seasons. As wild Aquilaria species is critical, the need for further development of fungal inoculants as a source to induce agarwood formation is required to meet the demand of agarwood trading worldwide. Further studies on the presence of secondary metabolites produced by inoculated agarwood should be conducted using gas chromatography-mass spectrometry (GC-MS). Besides, it is suggested to prolong the inoculation periods and increase the replication of agarwood inoculant to have a better understanding of the effect of fungus on Aquilaria species as a future potential agarwood inducer. 


\section{ACKNOWLEDGEMENT}

The authors would like to express their sincere gratitude for the research funding provided by the Special Grant Scheme of University Malaysia, Sarawak [vot no. F07/SpGS/1554/2017].

\section{REFERENCES}

Akhsan N, Sutisna M \& Mardji D. 2012. Pengujian model inokulasi Fusarium sp. pada pohon gaharu (Aquilaria microcarpa). Jurnal Kehutanan Tropika Humida 5: 48-55.

AZah MAN, Husni SS, Mailina J, Sahrim L, Majid JA \& Faridz ZM. 2013. Classification of agarwood (gaharu) by resin content. Journal of Tropical Forest Science 25: 213-219.

Barden A, Awang AN, Mulliken T \& Song M. 2000. Heart of the Matter. Agarwood Use and Trade and CITES Implementation for Aquilaria malaccensis. TRAFFIC, Cambride.

Battacharyy B, Datta A \& Barauah HK. 1952. On the formation and development of gaharu in Aquilaria agallocha. Science and Culture 18: 240-243.

Chнipa H \& Kaushiк N. 2017. Fungal and bacterial diversity isolated from Aquilaria malaccensis tree and soil, induces agarospirol formation within 3 months after artificial infection. Frontiers in Microbiology 8: 1-12. https://doi.org/10.3389/fmicb.2017.01286.

Cites (Conventional of Internal Trade in Endangered Species of Wild Fauna and Flora). 2015. Appendix II of Conventional of Internal Trade in Endangered Species of Wild Fauna and Flora. https://www. cites.org/sites/default/files/eng/app/2015/EAppendices-2015-02-05.pdf.

Gong LJ \& Guo SX. 2009. Endophytic fungi from Dracaena cambodiana and Aquilaria sinensis and their antimicrobial activity. African Journal Biotechnology 8: 731-736.

Hashim YZH, Kerr PG \& Abbas P. 2016. Aquilaria spp. (agarwood) as source of health beneficial compound: a review of traditional use, phytochemistry and pharmacology. Journal of Ethnopharmacology 189: 331360. https://doi.org/10.1016/j.jep.2016.06.055.

Karlinasari L, Indahsuary N, Kusumo HT, Santoso E, Turjaman M \& Nandika D. 2015. Sonic and ultrasonic waves in agarwood trees (Aquilaria microcarpa) inoculated with Fusarium Solani. Journal of Tropical Forest Science 27: 351-356.

LiU Y, Chen H, YANG Y et AL. 2013. Whole-tree agarwoodinducing technique: an efficient novel technique for producing high-quality agarwood in cultivated Aquilaria sinensis trees. Molecules 18: 3086-3106. https://doi.org/10.3390/molecules18033086.
LeE NY, Yunus MA, IdHam Z, Ruslan MS, AZIZ AH \& IrWANSYAH N. 2016. Extraction and identification of bioactive compounds from agarwood leaves. IOP Conference Series: Materials Science and Engineering 162: 1-6. doi:10.1088/1757-899x/162/1/012028.

Mohamed R, Jong PL \& Zali MS. 2010. Fungal diversity in wounded stems of Aquilaria malaccensis. Fungal Diversity 43: 67-74. https://doi.org/10.1007/s13225010-0039-z.

NAEF R. 2011. The volatile and semi-volatile constituents of agarwood, the infected heartwood of Aquilaria species. Flavour Fragrance Journal 26: 73-87. https:/ / doi.org/10.1002/ffj.2034.

Ng LT, Chang YS \& AzIzol AK. 1997. A review on agar (gaharu) producing Aquilaria species. Journal Tropical Forest Products 2: 272-85.

Pojanagaroon S \& Kaewrak C. 2005. Mechanical methods to stimulate aloes wood formation in Aquilaria crassna Pierre Ex H. Lec. (Kritsana) trees. Pp 161-166 in Jatisatienr A et al. (eds) Proceedings of III WOCMAP Congress on Medical and Aromatic Plants. Volume 2: Conservation, Cultivation and Sustainable Use of Medicinal and Aromatic Plants. International Society for Horticulture Science Acta Horticulture 676, Thailand. doi: 10.17660/ActaHortic.2005.676.20.

RAO KR \& Dayal R. 1992. The Secondary xylem of Aquilaria agallocha (Thymelaeaceae) and the formation of 'agar'. International Association of Wood Anatomists (IAWA) Bulletin 13: 163-172. https://doi. org/10.1163/22941932-90001264.

Semangun H. 2001. Introduction on Plant Pathology. Gadjah Mada University Press, Yogyakarta.

Santoso E, Pratini, Purnomo E, Irianto RSB, Wiyono B, Novriyanti E \& Turjaman M. 2011. Production and utilization technology for sustainable development of eaglewood (gaharu) in Indonesia. Technical report 3: Selection pathogens for eaglewood (gaharu) inoculation. (ITTO) PD 425/06 Rev. 1(I). The International Tropical Timber Organisation, Yokohama, Kanagawa.

TANG X. 2012. Chinese eaglewood inducer and bottle dripping method. https://www.google.com/ patents/CN102356772A?cl=en.

Zhang Z, Zhang X, Yang Y et al. 2014. Hydrogen peroxide induces vessel occlusions and stimulates sesquiterpenes accumulation in stems of Aquilaria sinensis. Plant Growth Regulation 72: 81-87. doi: 10.1007/s10725-013-9838-z.

Zhang Z, Yang Y, Meng H, Sur CH, Wei JH \& Chen HQ. 2010. Advances in studies on mechanism of agarwood formation in Aqularia sinensis and its hypothesis of agarwood formation induced by defense response. Chinese Traditional and Herbal Drugs 41: 156-159. 